\title{
Mudanças temporais no uso e cobertura do solo na bacia do reservatório de Peixe Angical, Tocantins
}

\author{
Temporal changes in use and land cover in the basin of Peixe Angical reservoir, Tocantins
}

\author{
Letícia Pereira dos Santos, Patrick Thomaz de Aquino Martins \\ ${ }^{1}$ Mestrado em Recursos Naturais do Cerrado, Universidade Estadual de Goiás, Campus Anápolis, GO, Brasil \\ santospear@gmail.com \\ ${ }^{2}$ Doutor em Geociências, Universidade Estadual de Goiás, Campus Minaçu, GO, Brasil \\ patrick thomaz@yahoo.com.br
}

\begin{abstract}
Resumo
Este trabalho teve como principal objetivo caracterizar os principais usos e cobertura do solo em uma escala temporal de dez anos, antes e após a formação do reservatório da usina de Peixe Angical no Tocantins. Além disso, relacionar o estado de conservação da bacia com características de declividade na área de estudo. Foram utilizadas imagens de satélite Landsat 5 e Landsat 8, para os anos de 2003, 2008 e 2013 para as quais aplicaram-se os seguintes procedimentos: registro, composição das bandas RGB, classificação supervisionada, avaliação da classificação e análise dos dados alcançados. Foram definidas cinco classes: vegetação remanescente, pastagem, água, solo exposto e queimada. A mais representativa foi de vegetação remanescente, ocupando $92,6 \%$ da área da bacia em 2013. A classe com maior aumento foi água, devido à formação do reservatório. O relevo da bacia, predominantemente plano, não é um dos fatores primordiais que explica o alto grau de conservação da bacia. Outros fatores como baixo grau de urbanização, poucas rotas de escoamento e solo pobre em nutrientes melhor explicariam o estado de conservação na área analisada. No entanto, apesar de a bacia, se apresentar bastante conservada, é necessário avaliar escalas espaciais maiores que abrangem a hidrografia de outras bacias.
\end{abstract}

Palavras-chave: Bacia hidrográfica. Impactos. Reservatório. Sensoriamento remoto. Uso do solo

\begin{abstract}
This work aimed to characterize the main uses and land cover on a time scale of ten years before and after the formation of the Peixe Angical reservoir in Tocantins. Moreover, relating the basin conservation status with slope characteristics in the study area. Satellite images were used Landsat 5 and Landsat 8, for the years 2003, 2008 and 2013 for which were applied the following procedures: registration, composition of bands RGB, supervised classification, evaluation of the classification and analysis of the obtained data. Five classes were defined: remaining vegetation, pasture, water, exposed soil and burned. The most representative was remaining vegetation, occupying 92.6\% of the basin area in 2013. The class with the highest increase was water due to reservoir formation. The relief of the basin, mostly flat, is not a primary factor that explains the high degree of conservation of the basin. Other factors such as low levels of urbanization, few flow routes and poor soil nutrients, had better explain the conservation status in the measured area. However, although the basin to present highly conserved, it is necessary to evaluate larger spatial scales covering the hydrography of other basins.
\end{abstract}

Keywords:Hydrographic basin. Impacts. Reservoir. Remote sensing. Land use 


\section{Introdução}

Alterações antrópicas que resultam em diversos tipos de uso e ocupação do solo afetam diretamente no funcionamento ecológico das paisagens naturais (PAPASTERGIADOU et al., 2007). Estas mudanças constituem nos impactos mais reconhecidos que afetam a diversidade biológica, estrutura e distribuição da vegetação (ALBERTI, 2005). A crescente modificação no uso da terra por áreas cultivadas, pastagens e ocupação urbana, por exemplo, são alguns exemplos dos impactos que modificam a vegetação natural (TANIWAK et al., 2013). Estas atividades ainda degradam os ecossistemas aquáticos, interferindo diretamente nos aspectos hidrológicos, físico-químicos e biológicos desses ambientes (ALBERTI, 2005; PAPASTERGIADOU et al., 2007).

Os ecossistemas terrestres e aquáticos são sistemas interligados que se interagem e realizam trocas de energia (REIS; FILHO, 2006). Grande parte da manutenção do nível da água em rios, por exemplo, é garantida em função da vegetação do entorno que regulam a quantidade de água escoada (TUNDISI; TUNDISI, 2010). Assim, a remoção da cobertura vegetal no entorno dos corpos d'água, e a substituição por atividades antrópicas vão interferir nos processos de infiltração e escoamento superficial, além de afetar a qualidade da água decorrente do despejo de nutrientes e sedimentação (TUNDISI; TUNDISI, 2010). O fósforo, por exemplo, é um importante nutriente para o desenvolvimento de vegetais, entretanto quando escoado para ambientes aquáticos promove o enriquecimento e em consequência ocorre o processo de eutrofização que afeta a qualidade da água (SHARPLEY et al., 1999; PAPASTERGIADOU et al., 2007).

Embora os ecossistemas terrestres interfiram sobre os recursos hídricos, estudos e monitoramentos do ambiente aquático frequentemente são realizados pela avaliação de parâmetros limnológicos (físicos, químicos e biológicos) em detrimento dos fatores de paisagens (GAMA et al., 2010). Outro aspecto negligenciado é a avaliação do uso do solo no entorno de ambientes aquáticos considerando a bacia hidrográfica, de rios e lagos (GAMA et al., 2010).

No Brasil, geralmente observam-se grandes modificações no estado trófico de reservatórios devido às alterações da paisagem na bacia hidrográfica que integra estes ecossistemas. Isto se explica pelo fato da bacia hidrográfica ser um sistema integrado de corpos hídricos onde os tipos de uso e ocupação do solo influenciam diretamente nos aspectos limnológicos e biológicos de seus cursos d'água (TUNDISI, 1993). Dessa forma, a bacia hidrográfica se torna a unidade mais viável para estudos que avaliam o uso do solo e gerenciam a qualidade da água em reservatórios e em ecossistemas aquáticos em geral (ROCHA; FREITAS; SILVA, 2014).

Um dos fatores que alteram as propriedades limnológicas em reservatórios, por exemplo, é a degradação do solo, proveniente da ocupação urbana, e do desmatamento, que provocam erosão e consequentemente contribui na sedimentação desses ambientes (TUNDISI, 2003). Além disso, o uso do solo voltado para as atividades agrícolas contribui para o fornecimento de nutrientes, como fósforo e nitrogênio provenientes de produtos químicos e fertilizantes que são escoados para dentro do curso d'água (PAPASTERGIADOU et al., 2007).

Além da importância em verificar o uso do solo em reservatórios hidrelétricos, outro aspecto importante é a avaliação destes fatores em escala temporal, que ainda são escassos em pesquisas (PAPASTERGIADOU et al., 2007). A informação do local de implantação do reservatório antes de sua operação permite identificar seus aspectos físicos iniciais, a cobertura vegetal original antes do enchimento, além das atividades de uso da terra que eram comuns na bacia hidrográfica (SANTOS; OLIVEIRA; SOUZA, 2013). Portanto a busca do conhecimento histórico do local anterior à formação do reservatório é importante para a compreensão de seu desempenho, além de permitir verificar os principais impactos antrópicos no ambiente terrestre sobre o ambiente aquático, ao longo do tempo (SANTOS; OLIVEIRA; SOUZA, 2013).

Dessa forma, o sensoriamento remoto enquanto geotecnologia é um importante recurso com aplicações em estudos de monitoramento de paisagens, sobretudo em reservatórios hidrelétricos. Esta tecnologia permite a obtenção de informação das características físicas, de cobertura do solo, bem como avaliação espacial e temporal da paisagem antes e depois da implementação do reservatório (ALCANTARA; NOVO; STECH, 2011). Além disso, o geoprocessamento realizado para análises de dados obtidos por meio de geotecnologias é uma ferramenta com ampla utilização em análises ambientais devido à facilidade de manipulação de imagens e avaliação de impactos em regiões de grandes extensões territoriais (CREPANI et al., 2001).

Os produtos do sensoriamento remoto e as ferramentas de geoprocessamento estão cada vez mais disponíveis para facilitar a obtenção de dados de cobertura da terra em bacias hidrográficas, possibilitando meios de identificar impactos na qualidade da água por meio da avaliação da paisagem (KEARNS et al., 2005). Neste contexto, o presente estudo tem como principal objetivo, identificar e caracterizar os tipos de uso e ocupação do solo na bacia hidrográfica de um reservatório hidrelétrico, antes e após o seu enchimento, numa escala temporal de 10 anos. Especificamente será verificado se há mudanças no tipo de uso do solo após a formação do reservatório; verificar se, após seu estabelecimento, a região do entorno do reservatório apresenta tendência de aumento ou diminuição dos impactos antrópicos; relacionar características de relevo com o grau de conservação e antropização na bacia de estudo. 


\section{Materiais e Métodos}

\section{1 Área de estudo}

O Rio Tocantins possui extensão de cerca de 2.750 $\mathrm{km}$, sendo um dos principais tributários do baixo Rio Amazonas. Junto com o Rio Araguaia formam a bacia Tocantins-Araguaia, que drena uma área de aproximadamente $760.000 \mathrm{~km}^{2}$. Atualmente o Rio Tocantins possui sete grandes barragens hidroelétricas em operação comercial (PELICICE; AGOSTINHO, 2012). O reservatório da Usina de Peixe Angical está localizado no alto Rio Tocantins (Figura 1), entre os municípios de Peixe, São Salvador do Tocantins e Paranã. A construção da Usina iniciou no ano de 2002. O enchimento do reservatório teve início em janeiro de 2006 e término em abril deste mesmo ano. A represa, com potência de 452 MW possui uma barragem de 39 metros de altura e 6,2 km de comprimento (SILVA et al., 2010).

O reservatório compreende uma área total inundada de $294 \mathrm{~km}^{2}$ em área de Cerrado, $120 \mathrm{~km}$ em extensão, profundidade média de 9,3 metros e tempo de residência da água de 18 dias (PELICICE; AGOSTINHO, 2012). Segundo Silva et al. (2010), a formação do reservatório resultou em intensos desmatamentos na região, assoreamento de rios e riachos e formação de lagos artificiais devido ao acúmulo de água.

O clima na região do reservatório é caracterizado como tropical, com temperaturas médias anuais de $26^{\circ} \mathrm{C}$ no período quente e chuvoso, que compreende os meses de outubro a março. No período seco (abril a setembro), a temperatura média anual é de $32{ }^{\circ} \mathrm{C}$. A precipitação média anual para o estado do Tocantins varia de 1.800 $\mathrm{mm}$, nas regiões norte e leste, a $1.000 \mathrm{~mm}$, na região sul (SILVA et al., 2010).

\subsection{Coleta e Processamento dos dados}

Para obtenção dos dados de uso e cobertura do solo foram utilizadas três imagens de satélite com intervalo de 5 anos entre cada uma e resolução espacial de 30 metros. Foi realizado o download de quatro cenas do satélite Landsat5, sensor TM, datadas do ano de 2003 (antes da formação do reservatório) e $\overline{2} 008$ (após a barragem), referentes as órbita-ponto 222-69, 222-68, 221-69 e 221-68, e três imagens do satélite Landsat 8, sensor OLI, de órbita-ponto 222-69, 222-68 e 221-69, para o ano de 2013. As escolhas das órbitas/pontos das cenas se deram com o intuito de abranger toda a área do entorno do reservatório, além das sub-bacias às quais o reservatório faz parte. As imagens escolhidas são referentes ao mês de julho de cada ano, devido a menor incidência de nuvens. As cenas imageadas pelo Landsat5 foram obtidas a partir do site do Instituto Nacional de Pesquisas Espaciais (INPE) - http://www.dgi.inpe.br/

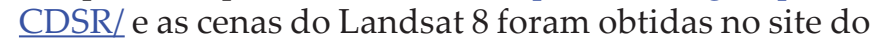

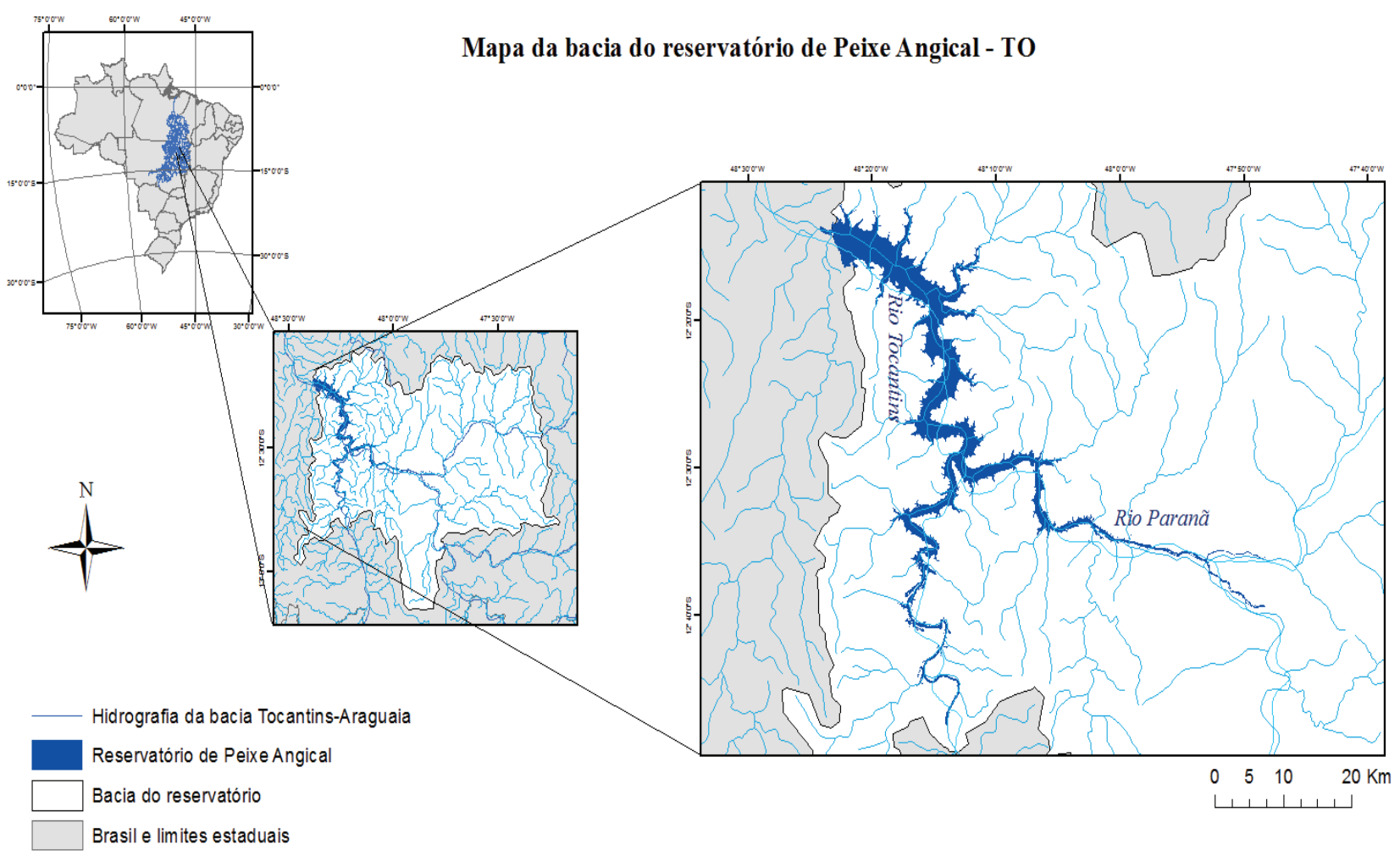

Figura 1 - Localização do reservatório e bacia da usina hidrelétrica de Peixe Angical em Tocantins (TO) 
Serviço Geológico dos Estados Unidos(USGS): http:// www.earthexplorer.usgs.gov.

Após a obtenção das cenas, foram feitos os registros das imagens do satélite Landsat 5 , com as composições coloridas RGB das bandas 5, 4 e 3, no programa ENVI 4.1. O registro refere-se ao georreferenciamento de uma imagem utilizando outra imagem base. Esta etapa consistiu na inserção de pontos de controle com o intuito de remover as distorções geométricas encontradas nas imagens. Foram utilizadas como base para o registro as imagens do Landsat 8, do ano de 2013, cujo sistema de projeção é o de coordenadas planas UTM (Universal Transverse de Mercator) e de referencial geodésico WGS-84, referentes às mesmas órbita-ponto das imagens de 2003 e 2008. Em seguida, foram criados os mosaicos das imagens, que consiste no agrupamento das cenas, para cada ano, nas mesmas composições coloridas das bandas 5, 4 e 3, para imagens do Landsat 5, e bandas 4, 5 e 6, para as cenas do Landsat 8 .

A partir dos mosaicos foi obtida apenas a área da sub-bacia à montante da barragem do reservatório, por meio do recorte da área de interesse no programa ArcGis 10.1. O limite da bacia para recorte da área foi obtido em formato shapefile no site da Agência Nacional de Águas: https://www.ana.gov.br.

A próxima etapa consistiu na classificação supervisionada das imagens, já com o recorte do formato da bacia. No programa ENVI 4.1, foram definidas, com base no conhecimento da área de estudo e observação das imagens de satélite, as seguintes classes: água, pastagem, vegetação remanescente, queimadas e solo exposto. Para cada classe foram definidas várias regiões de interesse que buscassem caracterizar a paisagem encontrada. Essa definição foi realizada com base na diferença das cores, nos valores dos pixels e também pelo formato da região. Após definição das classes foi escolhido o método de classificação supervisionada de máxima verossimilhança. Este método é o mais utilizado na classificação de imagens de satélite (RICHARDS; JIA, 1986). Para o método escolhido pressupõe-se que os valores de cinza dos pixels de cada classe apresentam distribuição normal (RICHARDS; JIA, 1986). Após a classificação foi obtido o valor do índice de Kappa, e a matriz de confusão.

Posteriormente foram feitas algumas edições das classes que não foram categorizadas corretamente pelo método escolhido, no programa ArcGis 10.1. Após o término das edições, foi obtido o mapeamento das classes e suas respectivas porcentagens para os anos de 2003, 2008 e 2013.

Para comparar o uso e cobertura do solo com a declividade do terreno da área da bacia foram usadas três imagens de relevo SRTM (Shuttle Radar Topography Mission) (MIRANDA, 2005) que abrangem a área da bacia do reservatório. Estas imagens foram obtidas com escala de 1:250.000 através do site Brasil em Relevo: http://www.relevobr.cnpm.embrapa.br. Após obtenção das imagens foi feito o mosaico no programa ENVI 4.1 e processamento e recorte da bacia no programa ArcGis 10.1. Em seguida obtiveram-se os valores em porcentagem e o mapa de declividade e valores em metros para a altitude.

\section{Resultados}

O índice Kappa, que avalia a classificação, foi de 0,96 para o ano de 2003 e 2008, com precisão global próxima a 97\%. Para o ano de 2013 foi de 0,97, com precisão aproximada a $98 \%$. Entretanto, foi necessária a edição de algumas classes de pastagens que foram confundidas com classes de vegetação de Cerrado do tipo campo, devido aos valores próximos dos pixels que representam estas classes.

Por meio da classificação supervisionada foi possível obter as seguintes classes (Figura 2):

Água: rios, a área alagada do reservatório de Peixe Angical para os anos de 2008 e 2013, e pequenos açudes.

Pastagem: pastagens encontradas na área da bacia;

Queimadas: áreas incendiadas para o período de passagem do satélite.

Vegetação remanescente: remanescente e vegetação natural características das diferentes fisionomias do bioma Cerrado.

Solo exposto: estradas e áreas sem cobertura de vegetação ou pastagens.

As sub-bacias do reservatório de Peixe Angical ocupam uma área de aproximadamente $9.325,72 \mathrm{~km}^{2}$. Ao longo dos 10 anos, houve supressão de área de vegetação natural de aproximadamente $2,45 \%$. As áreas de pastagens tiveram aumento de $0,61 \%$ de 2003 para 2013. Para as áreas de solo exposto, do ano de 2003 para o ano de 2013 teve uma diminuição de $0,42 \%$. As áreas de queimadas tiveram diminuição de 2003 para 2008, porém teve um baixo aumento de $0,06 \%$, para o ano de 2013 . Em relação ao enchimento do reservatório, a classe que agrega os corpos d'água classificados aumentou aproximadamente 2,16\% de 2003 para 2013. A tabela 1 mostra a porcentagem e a área $\mathrm{em} \mathrm{km}^{2}$ para cada classe encontrada para os anos de 2003, 2008 e 2013.

Em relação a topografia da área da bacia, o ponto de altitude mais baixa está a 201 metros de altura e o ponto mais alto a 1106 metros. A bacia apresenta relevo predominantemente plano (Figura 3), com declividade de 0 a $3 \%$ com abrangência de $86,95 \%$ da área total. A maior declividade varia de 20 a $45 \%$, com área que abrange apenas $0,96 \%$ da bacia (Tabela 2 ). 


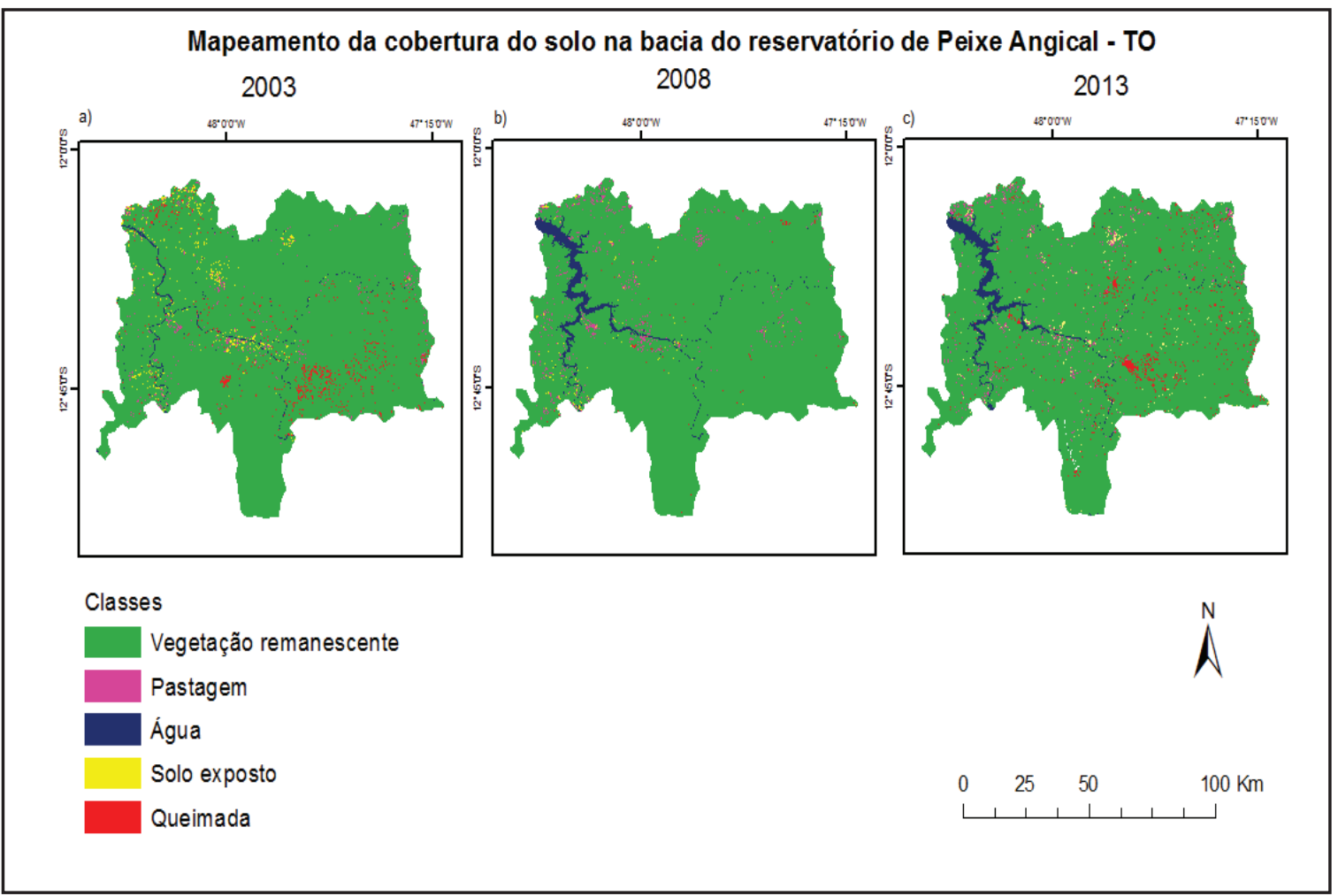

Figura 2 - Mapeamento das classes de uso e cobertura do solo na bacia do reservatório da Usina hidrelétrica de Peixe Angical no intervalo de dez anos: a) antes da formação da barragem em 2003, b) após a formação da barragem em 2008, e c) após a barragem em 2013

Tabela 1 - Área das classes de uso e cobertura do solo e proporção (\%) ocupada na bacia do reservatório da Usina hidrelétrica de Peixe Angical- TO para os anos de 2003, 2008 e 2013

\begin{tabular}{|c|c|c|c|c|c|c|}
\hline & & & & & \multirow{2}{*}{\multicolumn{2}{|c|}{2013}} \\
\hline Classes & \multicolumn{2}{|l|}{2003} & \multicolumn{2}{|l|}{2008} & & \\
\hline Vegetação remanescente & $8.861,23$ & 95,02 & $8.845,75$ & 94,85 & $8.635,36$ & 92,60 \\
\hline Pastagem & 92,10 & 0,99 & 143,69 & 1,54 & 149,06 & 1,60 \\
\hline Água & 89,35 & 0,96 & 288,80 & 3,10 & 291,07 & 3,12 \\
\hline Solo exposto & 107,17 & 1,15 & 27,86 & 0,30 & 68,22 & 0,73 \\
\hline Queimada & 175,87 & 1,89 & 19,63 & 0,21 & 182,01 & 1,95 \\
\hline Total & $9.325,72$ & 100 & $9.325,72$ & 100 & $9.325,72$ & 100 \\
\hline
\end{tabular}

Tabela 2 - Graus de declividade e porcentagens na área da bacia do reservatório da Usina hidrelétrica de Peixe Angical - TO

\begin{tabular}{llc}
\hline Categorias (EMBRAPA, 1979) & Declividade (\%) & $\begin{array}{l}\text { Porcentagem na área da } \\
\text { bacia (\%) }\end{array}$ \\
\hline Plano & $0-3$ & 86,95 \\
Suave-ondulado & $3-8$ & 8,17 \\
Ondulado & $8-20$ & 3,91 \\
Forte-ondulado & $20-45$ & 0,96 \\
Montanhoso & $45-100$ & - \\
Escarpado & $>100$ & - \\
\hline
\end{tabular}




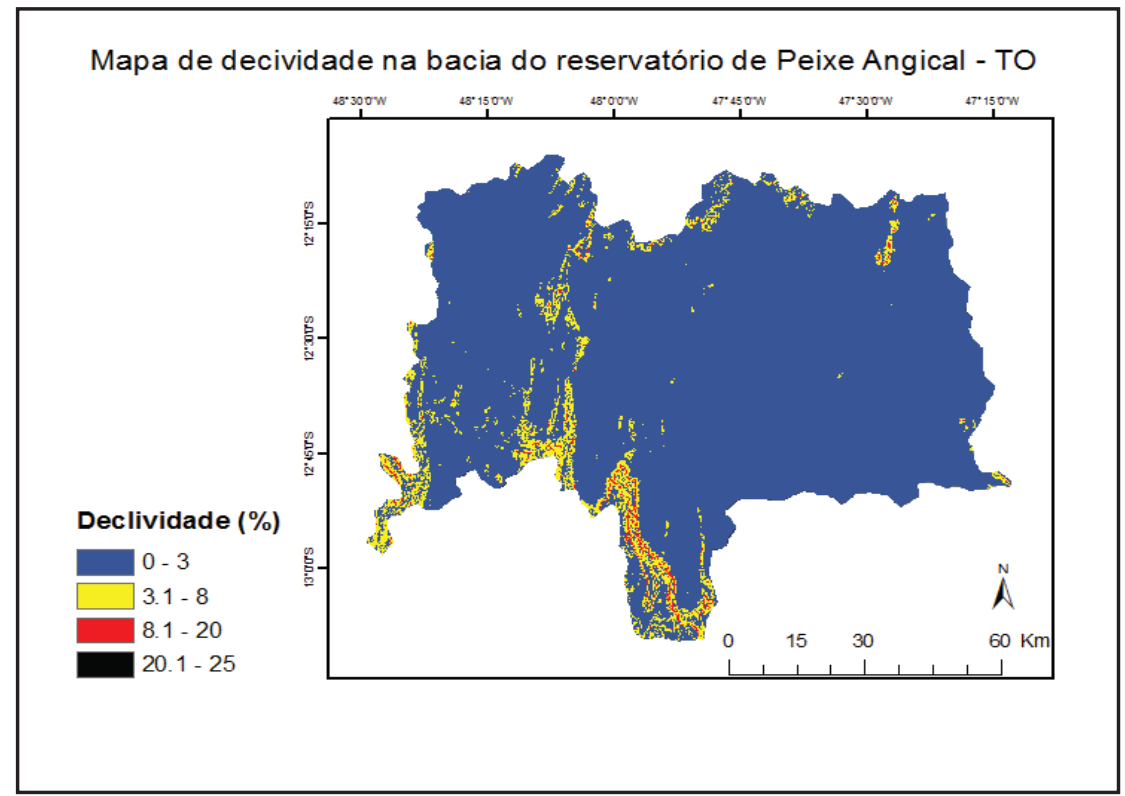

Figura 3 - Mapa de declividade da bacia do reservatório da Usina hidrelétrica de Peixe Angical

\section{Discussão}

Com base nos resultados obtidos, a área da bacia do reservatório de Peixe Angical no Tocantins se encontra bem preservada, apenas com baixas alterações no estado de conservação da vegetação natural ao longo dos dez anos. A alteração mais evidente foi o enchimento do reservatório da usina hidrelétrica de Peixe Angical, observado pelo aumento de sua área após a barragem (ver tabela 1). Os usos do solo encontrados que configuram em alterações antrópicas na área analisada são de áreas voltadas para a pecuária, solo exposto e queimadas. Não foi possível detectar, por meio da classificação, grandes áreas de agricultura. No entanto, é possível que haja a modalidade de agricultura de subsistência na região, das quais ocupam áreas próximas aos municípios e substancialmente menores, o que dificulta a classificação. Isso pode estar relacionado à resolução espacial de 30 metros dos satélites não diferenciarem com precisão estas pequenas áreas, de outras classes.

A diminuição das áreas de vegetação natural ao longo dos anos está relacionada ao aumento de áreas de pastagens e mais evidentemente pelo alagamento provocado na construção da barragem no rio Tocantins para formação do reservatório, devido a maior área inundada. Assim, o enchimento do reservatório contribui, inicialmente, com os impactos provocados no ambiente aquático, devido ao processo de decomposição de matéria orgânica da vegetação do entorno após o alagamento (GORDON; MEENTEMEYER, 2006).

O desmatamento provocado para o cultivo de pastagens foi observado em maior intensidade próximo às margens de rios, sobretudo nas proximidades do reservatório, antes, em fase de rio, e após seu enchimento. Atividades voltadas para pastagens provocam, pelo gado, a erosão e perda do solo. Consequentemente, o processo de assoreamento dos recursos hídricos é intensificado, o que, potencialmente, reduz o tempo de vida útil de hidrelétricas (CARVALHO, 2000). As áreas de pastagens próximas à disponibilidade hídrica do reservatório podem facilitar na dessedentação de animais. Este fato poderia explicar a maior concentração de áreas de pastagens próximas aos cursos d'água.

A ausência de vegetação no solo identificada na área da bacia, também contribui com o assoreamento dos recursos hídricos, devido à desestabilização do solo provocada pela perda de vegetação natural (TUNDISI; TUNDISI, 2010). Além disso, o solo exposto facilita o escoamento da água superficial proveniente da precipitação pluviométrica, que contribui com o transporte de sedimentos intensificando o assoreamento de rios e reservatórios (TUCCI; MENDES, 2006). Entretanto, a identificação de áreas de solo exposto por imagens pode ser variável, pois depende da data e época (seca ou chuva) de passagem do satélite (BASTIAANSSEN et al., 1998). Dessa forma, áreas que foram classificadas como solo exposto, próximas a pastagens, em época de seca, podem invariavelmente representar classes de pastagens em época chuvosa.

As áreas de vegetação com passagem pelo efeito do fogo, potencialmente não tiveram mudanças de 2003 para 2013. Porém, uma atenção deve ser dada a esta classe. As queimadas são bastante temporárias e seu quantitativo depende da época do ano em que são registradas. Com maior probabilidade de ocorrência na época seca devido a maior quantidade de matéria seca disponível. Portanto, seus efeitos também serão variáveis e mais temporários, o que explicaria a menor quantidade de áreas incendiadas no ano de 2008, por exemplo.

$\mathrm{Na}$ bacia caracterizada assim como na bacia de todo alto Tocantins, a vegetação predominante é típica de savana (FERREIRA; TOKARSKI, 2007). A ocorrência do 
fogo no cerrado é mais comum e frequente nesse tipo de vegetação, com consequências que afetam características fenológicas e reprodutivas das plantas e perda de nutrientes no solo (MIRANDA et al., 2002). Além disso, provoca eutrofização e alterações das características químicas de ambientes aquáticos devido ao escoamento de substâncias como bicarbonato, nitrato, amônio e nitrogênio orgânico provenientes das cinzas (FRANÇA; NETO; SETZER, 2007).

A área de relevo, predominantemente plana, poderia caracterizar a bacia com maior nível de degradação, o qual é propício à cultura agrícola, principalmente abaixo de $8 \%$ de declividade, em áreas de cerrado (MIZIARA; FERREIRA, 2006), como foi encontrado. Por outro lado, as áreas mais preservadas estariam localizadas em maiores altitudes e declives.

No estado de Goiás, locais de maiores altitudes e graus de declive são relacionados com áreas mais preservadas, enquanto que áreas planas apresentam maior grau de conversão do solo para atividades agropecuárias (CARVALHO; FERREIRA; BAYER, 2008). Entretanto, toda a bacia do reservatório, apesar de ser predominantemente plana, possui ainda grande porcentagem de remanescente de vegetação natural. Dessa forma, o relevo por si não explica a grande quantidade de área ainda preservada na bacia. No entanto, a própria topografia, que delimita a bacia, pode dificultar o acesso às áreas planas. Em áreas de cerrado, no oeste da Bahia, por exemplo, a topografia plana facilita tanto o acesso a estas áreas quanto o cultivo agrícola (BRANNSTROM et al., 2008).

A ausência de agricultura extensiva na região também pode estar relacionada às características do solo. Na bacia do alto Tocantins a predominância é do tipo latossolo, com deficiência em nutrientes, alto teor de alumínio e acidez, dependendo assim, de correções e mecanização do solo para o uso e cultivo de espécies agrícolas (FERREIRA; TOKARSKI, 2007), procedimento impeditivo para a região, devido ao baixo poder aquisitivo da população local. Além disso, a região possui poucas rotas de escoamento e baixa taxa de urbanização (FERREIRA; TOKARSKI, 2007).

De forma geral, os níveis de preservação e urbanização na área estão relacionados à ocupação do Cerrado, que se deu principalmente na década de 1920, com início da expansão no sul de Goiás (KLINK; MOREIRA, 2002). Tal ocupação se deu através de rotas vindas do sudeste, onde a ocupação do solo estaria saturada (KLINK; MOREIRA, 2002). Assim, a região norte do Cerrado, que inclui o estado do Tocantins, além do difícil acesso, se encontra distante de grandes centros econômicos e industriais, caracterizando áreas ainda bastante conservadas (SANO et al., 2010).

Assim, as principais ameaças à bacia analisada, apesar de serem baixas em comparação com a vegetação natural, são a conversão do solo para pastagens, áreas de solo exposto provocadas pelo desmatamento e expansão urbana que, apesar de não ter sido incluída na classificação, devido a sua baixa área de abrangência, possui potencial de ameaça à integridade da bacia.

A tendência, como observado, é que áreas de pastagens e degradadas cresçam em detrimento das áreas naturais de vegetação de cerrado. Áreas de queimadas em época de seca, apesar de serem temporárias, também podem se intensificar ao longo do tempo devido à expansão da urbanização e de áreas de pastagens que, muitas vezes, dependem do manejo do fogo para seu plantio.

Os impactos descritos afetam direta e indiretamente os ecossistemas aquáticos, em especial o reservatório de Peixe Angical. Apesar de a classe predominante ser de vegetação remanescente em toda a bacia, deve ser dada atenção, às consequências dos impactos que podem ser provocados. A remoção das florestas ripárias, por exemplo, altera diretamente o regime hídrico de rios e reservatórios, devido ao assoreamento, afetando a qualidade da água e do ambiente do meio aquático (TUCCI; MENDES, 2006).

Ainda, apesar do bom estado de conservação da bacia, as nascentes do rio Paranã, que desembocam diretamente na área de alagamento do reservatório no rio Tocantins, se encontram em estado de acelerada degradação (FERREIRA; TOKARSKI, 2007). Efluentes de esgoto doméstico, desmatamento, agrotóxicos e expansão da urbanização, por exemplo, são as principais ameaças à bacia do rio Paranã (FERREIRA; TOKARSKI, 2007). Devido à natureza hierárquica dos cursos fluviais na formação de uma bacia hidrográfica e às alterações que ocorrem em escalas menores, como em pequenos riachos, poderem modificar a integridade de rios de grandes ordens, uma atenção deve ser dada aos impactos que ocorrem em escalas espaciais ainda maiores (ALLAN, 2004), que vai além da análise da subdivisão hidrográfica do Tocantins-Paranã.

\section{Conclusões}

Por meio da utilização de imagens de sensoriamento remoto, foi possível mapear as classes de uso e cobertura do solo, ao longo de 10 anos, na bacia do reservatório de Peixe Angical, estado do Tocantins. As ferramentas utilizadas no processamento das imagens e dos dados foram bastante precisas para obtenção das classes. A maior predominância foi de vegetação remanescente na área analisada, indicando ainda um bom estado de conservação no entorno do reservatório, não relacionados estritamente à topografia e declive do terreno. Apesar da menor porcentagem de áreas ocupadas por impactos antrópicos como pastagens, e queimadas, foi observado que estas classes possuem uma tendência de aumento ao longo do tempo.

As principais consequências que podem ser mensuradas sobre os ecossistemas aquáticos são o assoreamento da água, provocada pela erosão por falta de vegetação ripária ao longo dos cursos d'água. Além disso, a falta 
de cobertura vegetal facilita, ainda, o escoamento de compostos orgânicos para o ambiente aquático provocando a eutrofização e afetando a qualidade da água e comprometendo a diversidade biológica.

Se observados em escalas ainda maiores, em consideração a hierarquia dos cursos fluviais, os impactos sobre o reservatório podem ser mais intensificados. Portanto, apesar do alto grau de preservação na região, é necessária a adoção de políticas públicas voltadas à conservação dos remanescentes de vegetação de Cerrado, além de garantir a conservação das áreas ainda não alteradas.

\section{Agradecimentos}

À Coordenação de Aperfeiçoamento de Pessoal de Nível Superior (CAPES) pela concessão de bolsa de estudos ao primeiro autor.

\section{Referências}

AGÊNCIA NACIONAL DE ÁGUAS. ANA- Biblioteca Virtual. 2014. Disponível em: <http://www.ana.gov.br/ bibliotecavirtual/solicitacaoBaseDados.asp>. Acesso em: 15 mai. 2014.

ALBERTI, M. The effects of urban patterns on ecosystem function. International Regional Science Review, v. 28, n. 2, p. 168-192, 2005.

ALCANTARA, E. H.; NOVO, E.M.L. M.; STECH, J.L. Novas tecnologias para o monitoramento e estudo de reservatórios hidrelétricos e grandes lagos. Rio de Janeiro: Parêntese, 2011. 277 p.

ALLAN, J. D. Landscapes and Riverscapes: The Influence of the Land Use on Stream Ecossystems. Annu. Rev. Ecol. Evol. Syst., v. 35, p. 257-284, 2004.

BASTIAANSSEN, W.G.M. et al. A remote sensing surface energy balance algorithm for land (SEBAL) I. Formulation. Journal of Hydrology, v. 212, p. 198-212, 1998.

BRANNSTROM, et al. Land change in the Brazilian Savanna (Cerrado), 1986-2002: Comparative analysis and implications for land-use policy. Land Use Policy, n. 25, p. 579-595, 2008.

CARVALHO, N. O. et al. Guia de avaliação de assoreamento de reservatórios. Brasília: ANEEL, 2000.

CARVALHO, T. M.; FERREIRA, M. E.; BAYER, M. Análise integrada do uso da terra e geomorfologia do bioma Cerrado: um estudo de caso para Goiás. Revista Brasileira de Geografia Física, v. 1, n. 1, p. 62-72, 2008.
CREPANI, E. et al. Sensoriamento remoto e geoprocessamento aplicados ao zoneamento ecológicoeconômico e ao ordenamento territorial. Instituto Nacional de Pesquisas Espaciais, São José dos Campos, 2001. 103 p.

EMPRESA BRASILEIRA DE PESQUISA AGROPECUÁRIA - EMBRAPA. Serviço Nacional de Levantamento e Conservação de Solos. Rio de Janeiro, 1979.

ESRI. ArcGIS Desktop: Release 10.1. Redlands, CA: Environmental Systems Research Institute. 2012.

FERREIRA, E. A. B.; TOKARSKI, D. J. Bacia Hidrográfica do Alto Tocantins: Retrato e Reflexões. ECODATA - WWF BRASIL, 2007.

FRANÇA, H.; NETO, M. B. R.; SETZER, A. O fogo no Parque Nacional das Emas. Braília: Ministério do Meio Ambiente, 2007.

GAMA, T. et al. Avaliação conjunta das variáveis físicas e químicas e do uso do solo do Rio Muriaé, município de Itaperuna, RJ. Revista de estudos ambientais, v. 12, n. 1, p. 63-72, 2010.

GORDON, E.; MEENTEMEYER, R. K. Effects of dam operation and land use on stream channel morphology and riparian vegetation. Geomorphology, v. 82, p. 412429, 2006.

INSTITUTO NACIONAL DE PESQUISAS ESPACIAIS. INPE - Catálogo de imagens. 2014. Disponível em:<http:// www.dgi.inpe.br/CDSR/>. Acesso em: 05 abr. 2014.

KEARNS, F. R.et al. A method for the use of landscape metrics in freshwater research and management.Landsc. Ecol., v. 20, 113-125, 2005.

KLINK, C.A.; MOREIRA, A.G. Past and current human occupation, and land use. In: OLIVEIRA, P.S.; MARQUIS, R.J. (Org.). TheCerrados ofBrazil. Nova Iorque: Columbia University Press, 2002. p. 69-88.

LANDIS, J. R.; KOCH, G. G.The measurement of Observer Agreement for Categorical Data.Biometrics, v. 33, p. 159-174, 1977.

MIRANDA, E. E. (Coord.). Brasil em Relevo. Campinas: Embrapa Monitoramento por Satélite. 2005. Disponível em: <http://www.relevobr.cnpm.embrapa.br>. Acesso em: 28 jun. 2014.

MIRANDA, H. S. et al. The FireFactor. In: OLIVEIRA, P.S.; MARQUIS, R.J. (Orgs.). The Cerrados ofBrazil. Nova Iorque: Columbia University Press, 2002. p.69-88. 
MIZIARA, F.; FERREIRA, N. C. Expansão da fronteira agrícola e evolução da ocupação e uso do espaço no Estado de Goiás: subsídios à política ambiental. In: FERREIRA, L.G. (Org.), Conservação da Biodiversidade e Sustentabilidade Ambiental em Goiás: Prioridades. Estratégias e Perspectivas. Goiânia: Canone, 2006. p. 94-109.

PAPASTERGIADOU, E. S. et al. Land use changes and associated environmental impacts on the Mediterranean shallow Lake Stymfalia, Greece. Hydrobiologia, n. 584, p. 361-372, 2007.

PELICICE, F. M.; AGOSTINHO, C. S. Deficient Downstream passage through fish ladders: the case of PeixeAngical Dam, Tocantins River, Brazil. Neotropical Ichthyology, v. 10, n. 4, p. 705-713, 2012.

REIS, J. T.; FILHO, W. P. Influência do uso e ocupação da terra no ecossistema aquático da sub-bacia hidrográfica do Arroio Cadena, em Santa Maria, RS. Ciência e Natura, UFMS, v. 28, n.1, p. 75-90, 2006.

RICHARDS, J. A; JIA, X.Remote Sensing Digital Image Analysis. $4^{\text {th }}$ edition. Berlin Heidelberg, Alemanha: Spring Verlag, 1986.

ROCHA, C. H. B.; FREITAS, F. A.; SILVA, T. M. Alterações em variáveis limnológicas de manancial de Juiz de Fora devido ao uso da terra. Revista Brasileira de Engenharia Agrícola e Ambiental, v. 18, n. 4, p. 431-436, 2014.

SANO, E. E. et al. Land cover mapping of the tropical savanna region in Brazil. Environ. Monit. Assess, v. 166, p: 113-124, 2010.

SANTOS, J. W. M. C.; OLIVEIRA, S. M. L.; SOUZA, W. P. Uso do solo e dinâmica dos nutrientes nas águas do reservatório da Hidrelétrica de Manso no Estado de Mato Grosso, Brasil Central. Revista franco-brasileira de Geografia, v.18, p. 1-22, 2013.

SHARPLEY, A. N.et al. National Research Project to Identify Sources of Agricultural Phosphorus Loss. Better Crops, v. 83, n. 4, p. 12-14, 1999.

SILVA, J. S. et al. Biodiversity and influence climatic factors on mosquitoes (Diptera: Culicidae) around the PeixeAngical hydroelectric scheme in the state of Tocantins, Brazil. Mem. Inst. Oswaldo Cruz, Rio de Janeiro, v. 105, n. 2, p. 155-162, 2010.

TANIWAKI, R. H. A influência do uso e ocupação do solo na qualidade e genotoxicidade da água no reservatório de Itapuranga, São Paulo, Brasil. Interciência, v. 38, n. 3, p. 164-170, 2013.
TUCCI C.; MENDES, A. C. Avaliação ambiental integrada de bacia hidrográfica. MMA: PNUD, 2006.

TUNDISI, J. G. The environmental impact assessment of lakes and reservoirs. In: SALÁNSKI, J.; ITSVÁNOVICS, V. (Org.) Limnological bases of lake management: proceedings of the I LEC/UNEP int. training course. Hungray: Ed. Tihany, 1993. p. 38-50.

TUNDISI, J. G. Gerenciamento integrado de recursos hídricos: novas perspectivas. Instituto Brasil PNUMA, Rio de Janeiro, n.75, p. 4-5, 2003.

TUNDISI, J. G.; TUNDISI, T. M. Impactos potenciais das alterações do Código Florestal nos recursos hídricos. Biota Neotropica, v. 10, n. 4, p. 67-75, 2010.

UNITED STATES GEOLOGICAL SURVEY.USGS - Science for a changing world. 2014. Disponível em: $<$ http://www. earthexplorer.usgs.gov>. Acesso em: 05 abr. 2014. 